\title{
Effect of Humidity on Self-heating of a Sub-bituminous Coal under Adiabatic Conditions
}

\author{
YULIANTO S NUGROHO, RUDY R RUSTAM, IMAN and MUKSIN SALEH \\ Department of Mechanical Engineering \\ University of Indonesia \\ Kampus UI Depok 16424, West Jawa, Indonesia
}

\begin{abstract}
A spontaneous increase in coal temperature with a possible transition into fires represents a direct hazard to coal storage and transportation. This paper evaluates the self-heating characteristics of a sub-bituminous coal under adiabatic oxidation conditions. This paper assesses the effect of relative humidity of the gas supply on the self-heating rates of coal. It is shown that an increase in the gas supply relative humidity has a marked affect on the self-heating rates of the coal. In this work the sub-bituminous coal sample undergo oxidation most rapidly when the relative humidity of the gas supply is about $70 \%$. The effect of relative humidity decreases as oxygen concentration in the gas supply increases. A practical consequence of this finding is that improved fire safety measures should be considered during sub- bituminous coal related operations in hot and humid regions.
\end{abstract}

KEYWORDS: self-heating, risk assessment, adiabatic oxidation method, coal.

\section{INTRODUCTION}

High-moisture low rank coals have been found to be more suitable for domestic use due to low heat output and self-heating problems upon long term storage and transportation. Some major damage related to spontaneous combustion of coal is summarized [1]. Recent increase in utilization of high-moisture low rank coals following oil price rise has necessitated understanding fire safety aspects of coal storage and transport especially in humid and high ambient temperature conditions. In general, the spontaneous combustion of a coal pile are significantly affected by many factors including coal rank, the oxygen content of the coal, the flow rate of the air, particle size, the moisture content of the coal and the humidity of the air [1-6].

Moisture plays an important role on behavior of coals in stockpiles. The complex processes of self-heating in the existence of water have been investigated by many workers [2-4]. The amount of water contained by coal for a given value of relative humidity is described by its adsorption and desorption isotherm. The interaction between water and coal can be exothermic or endothermic depending on whether the water condenses or evaporates. In sufficient quantities, water suppresses self-heating by blocking access of oxygen to active sites and by taking up the heat released by oxidation as it occurs. However, if the moisture content of the coal is lowered, it may be expected that these moderating effects will become less effective and a significantly greater level of self-heating will occur [2]. In addition, it has been reported that low rank coals undergo the highest heating rate when their moisture content is reduced to about one-third of the original as-received moisture content [5]. On the contrary, the liability of spontaneous of a low-moisture Turkish lignite was increased by increasing moisture content of the coal above its as-received value [3].

A number of laboratory methods have been developed to study the propensity of coal to ignite spontaneously. The testing conditions of the suggested methods were for the most parts quit different from those actually encountered by stockpiles. For example, the suggested test methods and the correspondent oven temperature range are (i) basket method, including Frank-Kamanetskii and the crossing-point temperature (CPT) methods $\left(100\right.$ to $180^{\circ} \mathrm{C}$ ), and (ii) crossing point method, CPT (130 to $200^{\circ} \mathrm{C}$ ) [1,3]. Studies on the storage of bagasse [7] showed conclusively that the usual high temperature small sample basket ignition tests were not capable of being extrapolated to the practical low temperature-occurs in the large size case.

Adiabatic oxidation test consists of measuring the temperature rise in a coal sample reacting with oxygen under adiabatic conditions. The latter are commonly achieved using a temperature controlled oil bath [6] and adiabatic oven [8,9], within which the sample is enclosed, and increasing the temperature of the oven to match that recorded by a thermocouple within the sample. 
After being neglected for sometimes, the use of an adiabatic oxidation method for studying the self-ignition of coal gained new attentions [8]. Progress in electronic process control equipments can effectively reduced the practical difficulties involved in the adiabatic oxidation approach. The use of the adiabatic oxidation approach to study the effect of moisture content has been reported by Beamish, B.B., et al. [8]. They concluded that as the moisture content of the coal was progressively increased, from the dry state of the test, the self-heating index value of Callide coals decreased dramatically. The self-heating rate becomes measurable at approximately $40-50 \%$ of the moisture holding capacity of the coal. Above this critical level of moisture content, the heat produced by oxidation is dissipated by moisture evaporation and coal selfheating is significantly delayed. More recently, using similar method it has been reported that an Indonesian high-moisture sub-bituminous coal was found to undergo oxidation most rapidly when its moisture content was reduced to about $25 \%$ of the original as-received value [10].

In tropical countries, the fire safety aspect of coal related operations should also consider the affects of high relative humidity and ambient temperature. Since all coal and storage piles are exposed to air with some relative humidity, a quantitative knowledge of the influence of humid environment to self-heating rate is important. Using the Crossing Point Method (CPT), Küçük, A., et al. [3] reported that the liability of spontaneous combustion of a low-moisture lignite was increased with decreasing humidity of the air. However, B.F. Gray et al. [11] showed that increasing relative humidity outside the pile can cause ignition of a pile in a stable steady state already attained by exposure to a lower external relative humidity. In addition, some theoretical work in this problem has been carried out by McIntosh et al., where it was shown that if a lump of reactive material is initially dry and sub-critical, a slight change in the atmospheric humidity can have a marked affect on the ignition characteristics of the material [12]. In the present study, the adiabatic oxidation method [8] was used to evaluate the effect of relative humidity in gas supply on the self-heating characteristics of a high-moisture sub-bituminous coal from Indonesia.

\section{EXPERIMENTAL SET-UP}

The sub-bituminous coal sample was provided directly from the mine-site and sent in a plastic container air sealed, containing approximately $10 \mathrm{~kg}$ of coal, mostly in lump form. In order to minimize unnecessary oxidation, the sample was maintained in lump condition and was kept undisturbed in the laboratory prior to each test. After the test facility was ready, the plastic bag was unwrapped and the sample was crushed to $<250 \mu \mathrm{m}$ (60 mesh) just before each run - in order to minimize the effects of oxidation on fresh surfaces created by the grinding of the coal. Each test requires $200 \mathrm{~g}$ of crushed coal. The analytical data for the coal is presented in Table 1. The coal sample is low in sulfur and low in ash.

Table 1. Analytical data for the sub-bituminous sample (air-dried basis)

\begin{tabular}{|l|r|}
\hline \multicolumn{1}{|c|}{ Properties } & \% \\
\hline Moisture & 21.26 \\
\hline Ash & 2.86 \\
\hline Volatile matter & 34.96 \\
\hline Fixed carbon & 40.92 \\
\hline Total sulfur & 1.35 \\
\hline
\end{tabular}

Figure 1. gives the schematic diagram of adiabatic oxidation system. This experimental apparatus is developed on the basis of the basic design presented by Beamish, B.B. et al. [8]. The apparatus consists of an electric oven, the reactor vessel and its associated connections, gas supply metering system, temperature measurement and control system, and data acquisition system. The oven is equipped with heating elements and a fan located at the rear of the oven for ensuring temperature distribution inside the oven. The reaction vessel is a $250 \mathrm{ml}$ vacuum stainless steel thermos that is equipped with a specially design plug and seals. The fresh gas supply into the reactor is provided by a copper tube. Another tube is used as an exhaust. Before the fresh gas (either nitrogen or oxygen) is supplied into the reactor, the gas is conditioned in a $32 \mathrm{~m}$ copper pipe fitted on the door of the oven. Type $\mathrm{K}$ thermocouples are used to monitor the oven and coal temperatures. The manufacturer's accuracy of this thermocouple is $\pm 2.5 \mathrm{~K}$.

A temperature controller of Autonics TZ4ST is used to govern the temperatures of oven and coal during drying process in nitrogen. Meanwhile, during the adiabatic oxidation mode, the oven temperature is 
carefully controlled by a micro-controller, a solid state relay Opto 22 and a special computer program. The output of thermocouple readings are recorded in a PC via ADAM modules of Advantech. Once the experiment has completed the data is saved in the hard disk for further analysis.

Besides the standard adiabatic testing apparatus, in this work, a hot water bath humidifier consists of a container with a thermostatically controlled heating element and tubing with water traps is also used. The relative humidity of supply gas is controlled by water bath temperature and monitored continuously using a humidity meter. During a typical run, the fluctuations observed in the relative humidity are within $\pm 4 \%$.

An initial temperature of $40^{\circ} \mathrm{C}$ was chosen in this work to represent close conditions in real stockpiles. The rate of spontaneous heating of coal is dependent on the accumulation of heat generated from its oxidation reaction. It is therefore essential that an ideal condition should be created for the accumulation of heatreflecting the heating potential of coals. In this experiment an air flow rate of $50 \mathrm{ml} / \mathrm{min}$ were used.

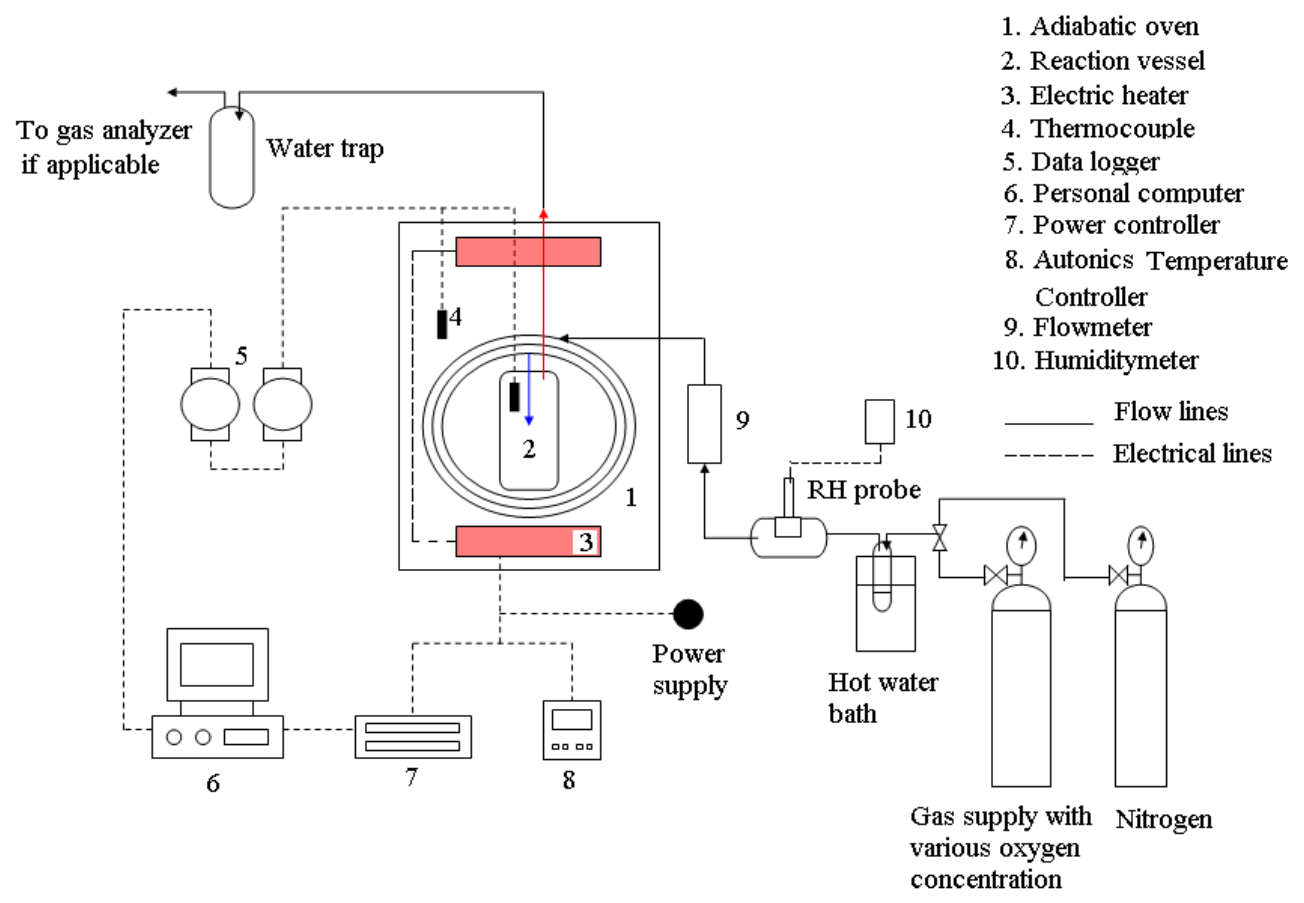

Fig. 1. Schematic diagram of adiabatic oxidation test system.

\section{Procedure}

Coal sample of known weight of $200 \mathrm{~g}$ was poured carefully into the reaction vessel. In a typical run, a coal sample was dried under nitrogen at $105^{\circ} \mathrm{C}$ for approximately $20 \mathrm{~h}$ to ensure complete drying. During drying process, the flow rate of nitrogen was maintained at $200 \mathrm{ml} / \mathrm{min}$ enabling effective removal of water vapor from the reaction vessel. After 20 hours, the oven setting temperature was lowered to $40^{\circ} \mathrm{C}$ (the cooling period of the dried sample) with nitrogen still passing through it. At a time during the cooling, the reactor vessel was gently tapped to ensure that no air pockets developed around the tips of the thermocouples. When the sample temperature has stabilized at $40^{\circ} \mathrm{C}$, the oven was switched to adiabatic mode controlled by a special computer program and the gas selection switch turned to oxygen with a constant flow rate of $50 \mathrm{ml} / \mathrm{min}$. The temperature of the coal and the oven were recorded by a data logging system for later analysis. A typical test was completed when the sample temperature reached approximately $200^{\circ} \mathrm{C}$. After the oven cooled down, the sample was removed from the reaction vessel and it was cleaned in preparation for the next test. In the present work, the adiabatic oxidation tests are carried out in dry and humid conditions. The gas for the dry run (relative humidity, $\mathrm{RH}<4 \%$ ) was supplied directly from the gas cylinder. Meanwhile, for the humid tests $(\mathrm{RH} \geq 70 \%$ ), the gas supplies were obtained by conducting the gas 
stream through the water bath. The gas supply for the adiabatic oxidation tests was delivered from three different gas cylinders having oxygen concentrations of $44 \%, 71 \%$ and $96 \%$, respectively.

\section{Self-heating curves analysis}

The self-heating curves are analyzed on the basis of (i) the self-heating rate index, $\mathrm{R}_{70}$ as the gradient of the linear portion of the adiabatic self-heating curve from $40^{\circ} \mathrm{C}$ to $70^{\circ} \mathrm{C}$ [8], and (ii) the time taken to reach $400 \mathrm{~K}\left(\sim 127^{\circ} \mathrm{C}\right)$. The significance of about $400 \mathrm{~K}$ ambient temperature for small-scale experiments was suggested by Nugroho et.al. [13]. It was concluded that a critical ambient temperature of about $400 \mathrm{~K}$ was found for all coal samples when crushed into $0.06 \mathrm{~mm}$ particles of diameter and tested using a $50 \mathrm{~mm}$ cubical basket. In addition, Mahadin et al. [9] suggested that the temperature profile of low temperature oxidation under adiabatic conditions can be divided into two zones below and above $127^{\circ} \mathrm{C}$.

\section{RESULTS AND DISCUSSION}

Figure 2 shows a plot of coal sample temperature and oven temperature against time for the initial test. It clearly demonstrates the oven's ability to track the self-heating of the coal and minimize heat losses during the process. A close observation of the temperature fluctuations (the insert) clearly shows that the sample temperatures seem to have better stability than the oven temperatures. Temperature fluctuation of about $\pm 0.5^{\circ} \mathrm{C}$ is acceptable for the adiabatic approach which relies on the ability of the oven to follow sample temperatures.

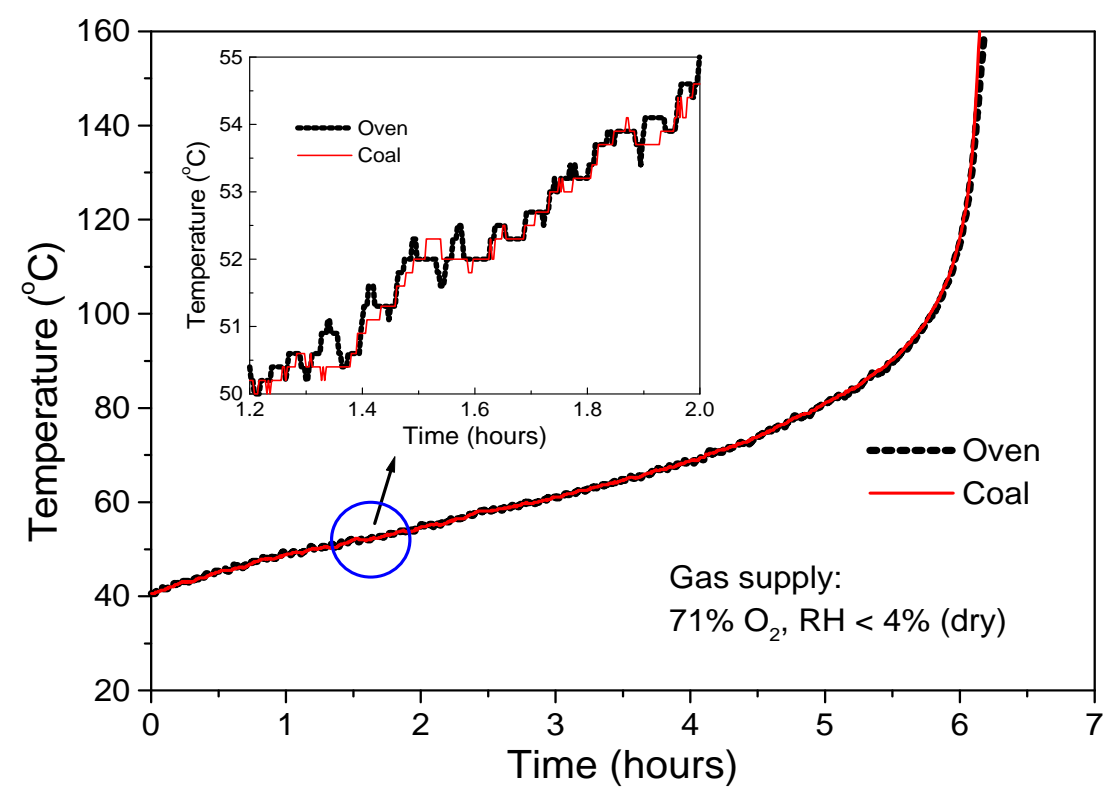

Fig. 2. Comparison of coal and oven temperatures for testing of the coal sample using dry gas supply of $71 \% \mathrm{O}_{2}$. Detail temperature fluctuations are given as an insert.

In Fig. 2 the time axis started when the oven was switched to adiabatic mode and the gas selection switch turned to oxygen with a constant flow rate of $50 \mathrm{ml} / \mathrm{min}$. The rapid increase of temperature at the beginning of the process is due to the exothermic oxidation reaction of the active sites of the coal once oxygen has been introduced. After sometimes, the sample temperature increases steadily to $70^{\circ} \mathrm{C}$. Beyond this point the sample temperature rises exponentially (Fig. 3). The heat accumulation within the sample bed increases the sample temperature and enhances the oxidation reaction of the coal. Following the Arrhenius law, the temperature and the corresponding rate of rise in temperature, increase exponentially. This self-heating mechanism can lead to a phenomenon known as spontaneous combustion. The corresponding self-heating rate, $R_{70}$ is found to be $7.3^{\circ} \mathrm{C} / \mathrm{h}$. This $R_{70}$ value is lower than the instantaneous self-heating rate $(\mathrm{d} T / \mathrm{d} t)$ at 
$70^{\circ} \mathrm{C}$ of about $10^{\circ} \mathrm{C} / \mathrm{h}$. The self-heating rate values plotted in Fig. 3 are limited to $50^{\circ} \mathrm{C} / \mathrm{h}$ due to scale reasons. In fact, the rate value can reach well above $200^{\circ} \mathrm{C} / \mathrm{h}$ in un-controlled spontaneous combustion stages. The $R_{70}$ values for the various parameters studied are shown in Table 2.

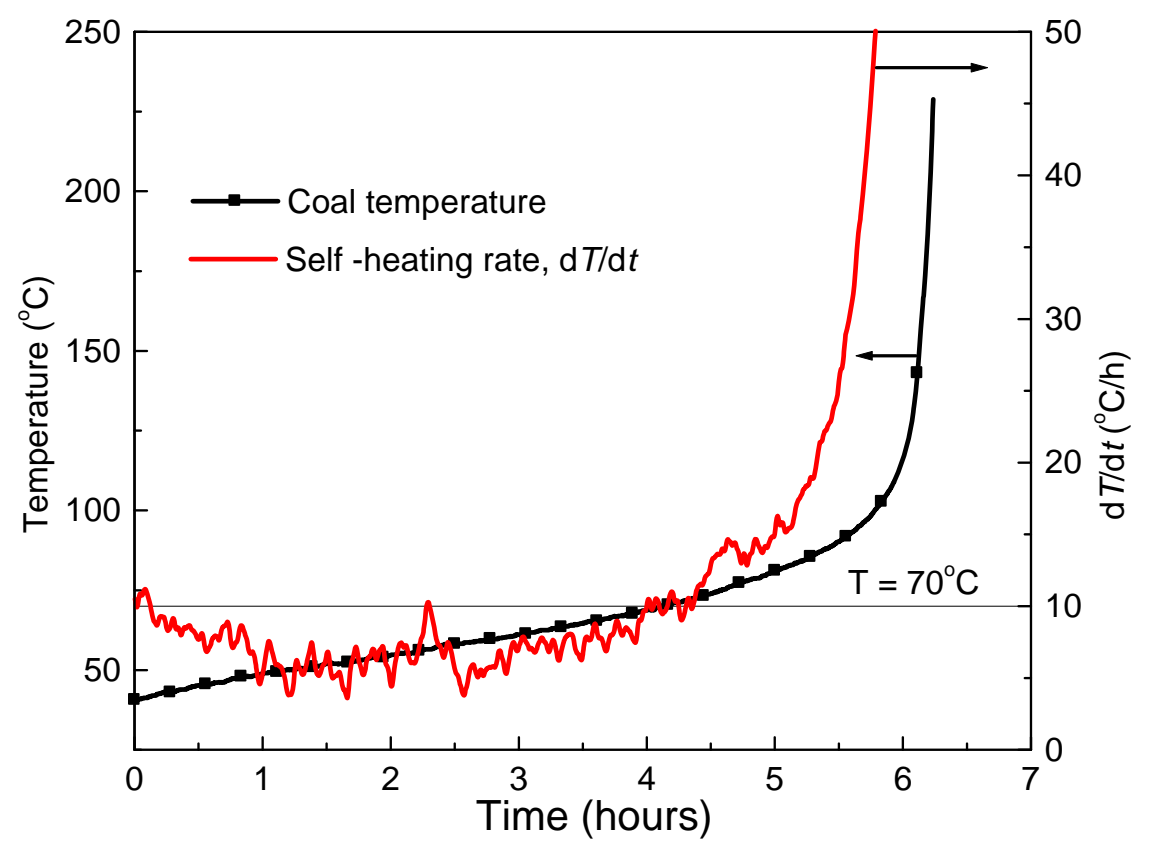

Fig. 3. The corresponding rate of temperature increase of coal sample in Fig. 1.

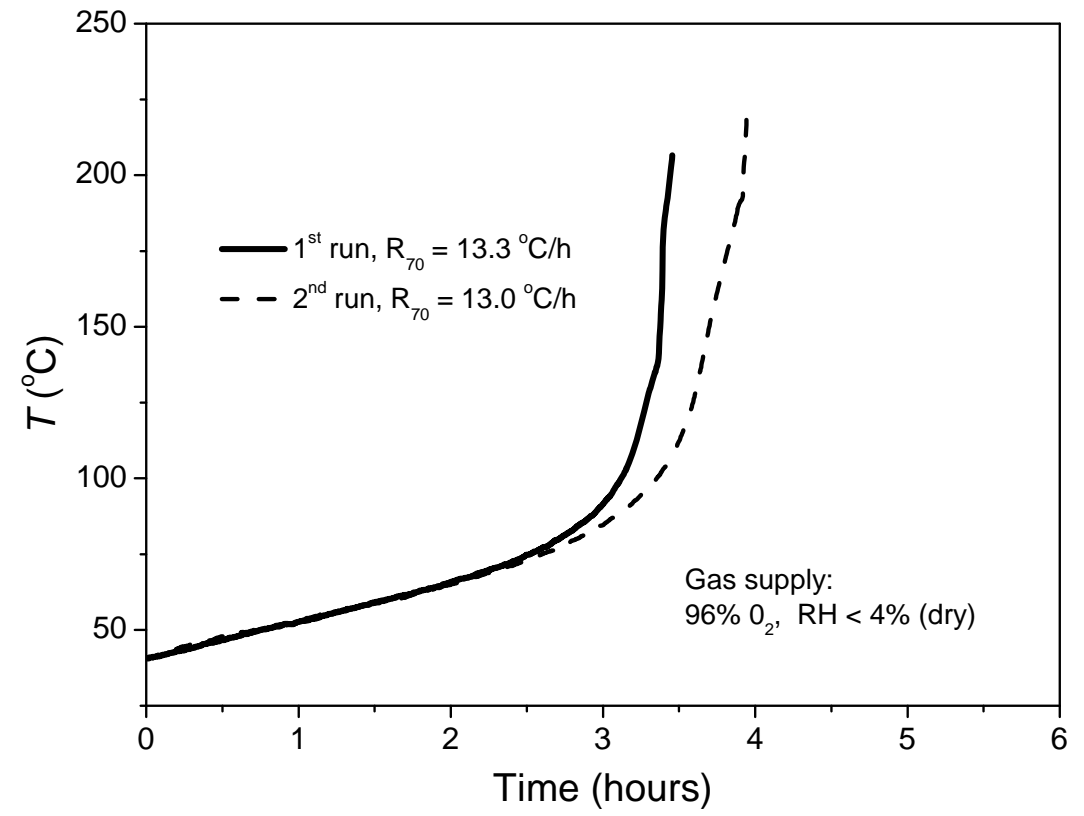

Fig. 4 Repeat self-heating profiles for the coal tested in gas supply of $96 \% \mathrm{O}_{2}$ at dry conditions.

The results of the repeat tests performed on the coal sample using $96 \% 0_{2}$ at dry conditions are shown in Fig. 4. The repeat test $\left(2^{\text {nd }}\right.$ run) was carried out 65 days after the $1^{\text {st }}$ run. However, both tests showed good 
agreement particularly during the initial period of oxidation where the $\mathrm{R}_{70}$ values were deduced. Given the time period between tests, it is possible that the deviation between 3.5 to $4 \mathrm{~h}$ could be attributed to oxidation during storage. The self-heating rate $\left(\mathrm{R}_{70}\right)$ values obtained of $13.3^{\circ} \mathrm{C} / \mathrm{h}$ and $13.0^{\circ} \mathrm{C} / \mathrm{h}$ have an acceptable repeatability.

Table 2. Summary of measured $R_{70}$ and Time to $127^{\circ} \mathrm{C}$ values.

\begin{tabular}{|c|c|c|c|}
\hline $\mathbf{O}_{\mathbf{2}}$ concentration in gas supply (\%) & $\mathbf{R H} \mathbf{( \% )}$ & $\left.\mathbf{R}_{\mathbf{7 0}} \mathbf{(}^{\mathbf{0}} \mathbf{C} / \mathbf{h}\right)$ & Time to $\mathbf{1 2 7} \mathbf{0}^{\mathbf{0}} \mathbf{~ ( h )}$ \\
\hline 44 & $<4$ & 6.2 & 11.2 \\
\hline 44 & 70 & 12.5 & 4.3 \\
\hline 44 & 90 & 8.9 & 6.4 \\
\hline & & & \\
\hline 71 & $<4$ & 7.3 & 6.1 \\
\hline 71 & 70 & 11.3 & 4.3 \\
\hline 71 & 90 & 8.8 & 5.2 \\
\hline 96 & & & \\
\hline 96 & $<4$ & 13.3 & 3.3 \\
\hline 96 & 70 & 14.4 & 3.4 \\
\hline & 90 & 11.5 & 4.0 \\
\hline
\end{tabular}

Figures 5-7 show the self-heating curves of the coal at various relative humidity of the gas supply. In general, when the dried coal samples were exposed to oxygen, immediate exothermic responses were observed. It is clearly shown in Fig. 5 that oxygen concentration in the gas supply greatly affected the initial rate of exothermic reactions and the time to reach $127^{\circ} \mathrm{C}\left(t_{127}\right)$. As given in Table 2, in dry conditions, the $\mathrm{R}_{70}$ values increased relatively to oxygen concentration. Inversely, the $t_{127}$ values reduced following the addition of $\mathrm{O}_{2}$ concentrations in gas supplied. Meanwhile, Figs. 6 and 7 illustrated conditions where moist air interacting with dry coal. As the moist gas supply entered the reaction vessel, the dry coal surfaces adsorbed the moisture in the gas supply. The heat release upon hydration liberated sufficient heat to raise the temperature of dry coal which already had lower heat capacity due to prior drying. This finding is in agreement with the work of others [11,12].

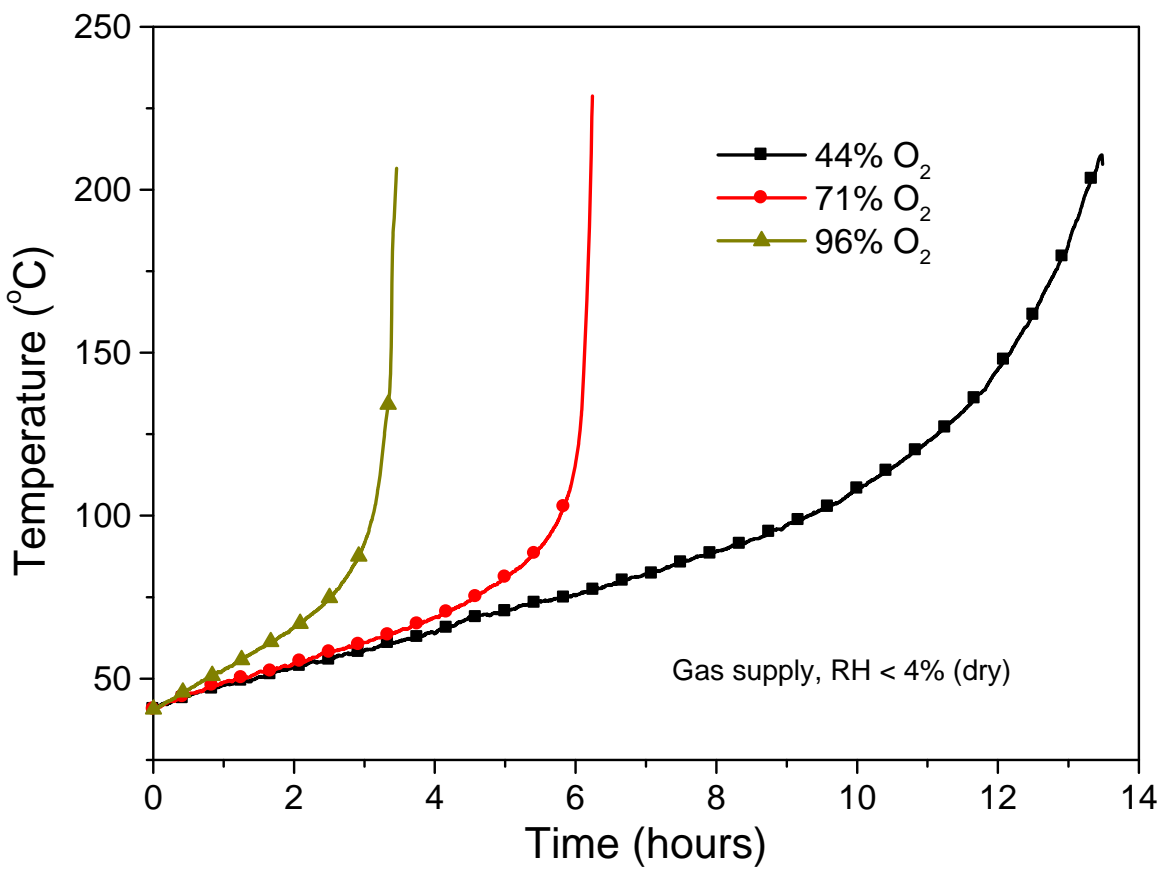

Fig. 5. Self-heating curves showing the effect of oxygen concentration in gas supply at dry conditions. 


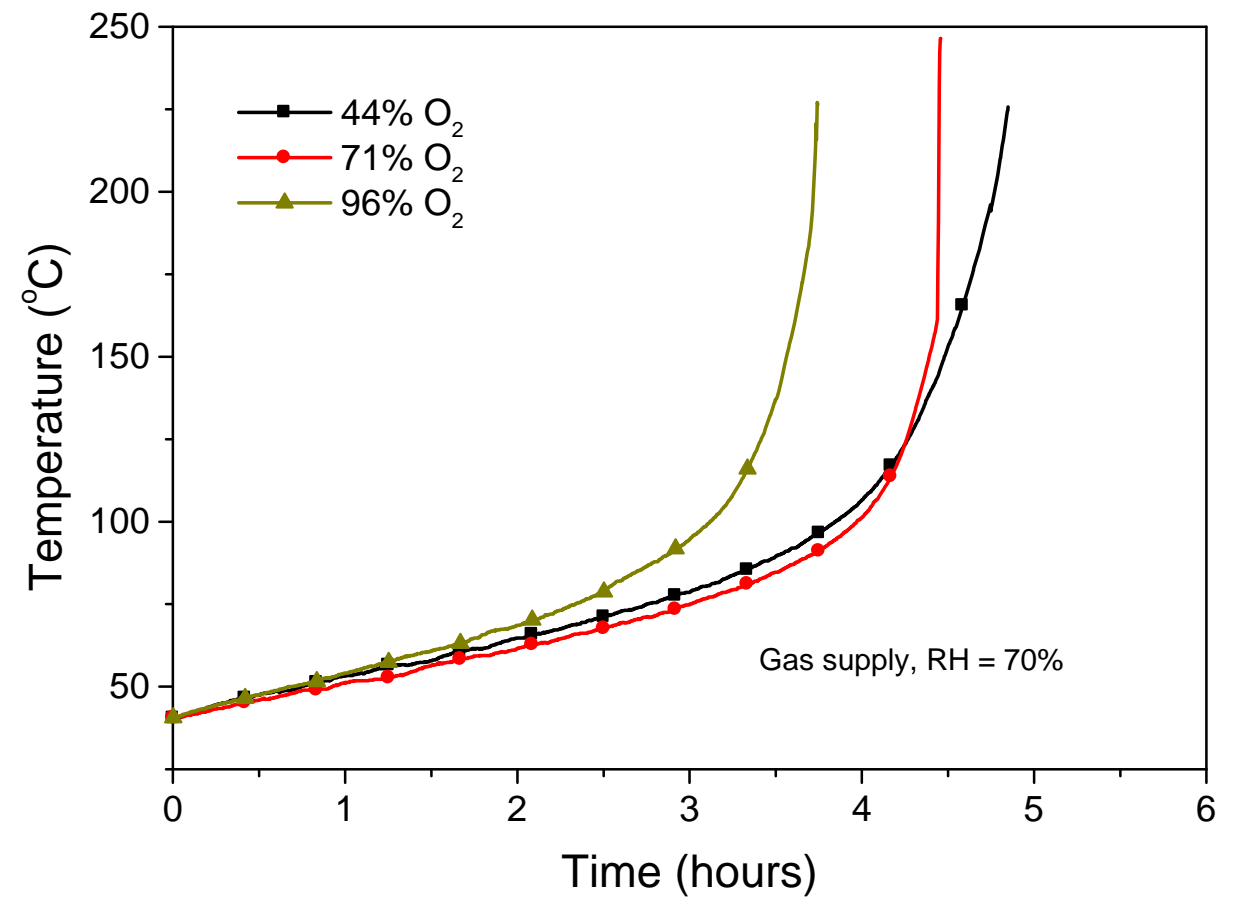

Fig. 6. Self-heating curves showing the effect of oxygen concentration in gas supply at a constant relative humidity of $70 \%$.

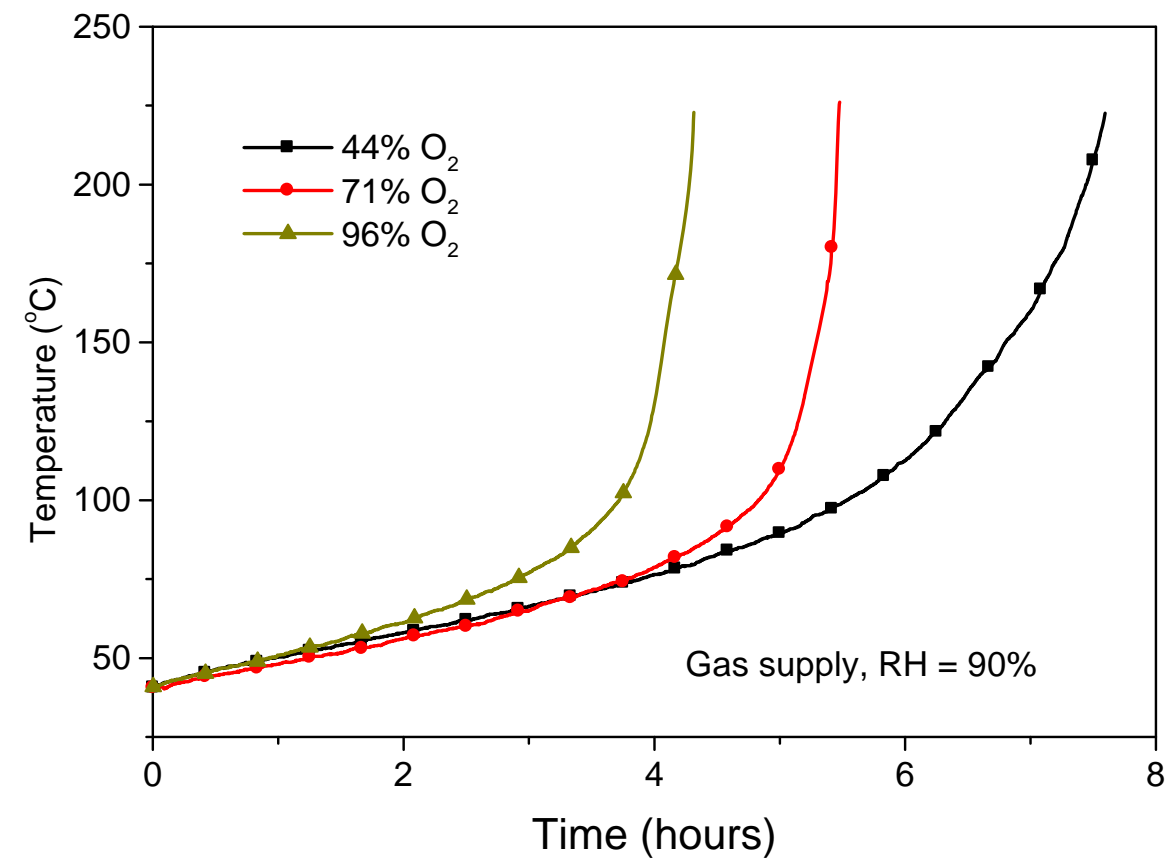

Fig. 7. Self-heating curves showing the effect of oxygen concentration in gas supply at a constant relative humidity of $90 \%$. 
The effect of relative humidity on the self-heating curves at various oxygen concentrations is given in Figs. 8-10. For all oxygen concentrations applied, the effect of humidity to the self-heating rates increased as the relative humidity of the supply gas moved from dry to $70 \%$. If a dry coal is exposed to an atmosphere of fixed relative humidity, it will gain moisture until equilibrium is reached. Increasing the relative humidity of the surrounding will then cause the coal to gain more moisture to reach another equilibrium state [14]. On the other hand, an increase in the humidity causes an uptake of moisture in coal which leads heat generation. This heat is in addition to that heat generated from oxidation. Therefore it was clear that oxidation of dried-coal in a humid atmosphere released more heat as represented by higher $\mathrm{R}_{70}$ values in Figs. 8 and 9. However, at a higher value of $90 \%$ relative humidity, the self-heating rates slightly lessened compared to at $70 \%$ one.

As shown in the $3^{\text {rd }}$ and $4^{\text {th }}$ columns of Table 2, there is an optimum trend on the effect of relative humidity of gas supply on the $\mathrm{R}_{70}$ and $t_{127}$ values. The optimum trend obtained might correlate with the amount of moisture gained by the dry coal. In order to estimate the rate of hydration for the dry sample, the experimental data and predictions obtained by Monazam et al. [14] was considered. Their experimental data was for a dry Wyoming char at $25^{\circ} \mathrm{C}$ and relative humidity $(\mathrm{RH})$ of $30 \%$ and $80 \%$. Within the period of two hours, the moisture content of the dry char increased from about $1 \%$ to $2 \%$ (at $30 \% \mathrm{RH}$ ) and $5 \%$ (at $80 \% \mathrm{RH}$ ), respectively. On the other hand, the author's previous work [10] using a slightly higher moisture content sub-bituminous coal showed that the sample's undergo oxidation most rapidly when its moisture content was about $5 \%$ or one-forth of the original as-received value. We speculate that the humid gas supply having $70 \%$ relative humidity may increase the moisture content of the dry coal to an optimum value that accelerates the self-heating rates. Since the moisture uptake was higher in a more humid atmosphere (at $90 \% \mathrm{RH}$ ), as expected the $\mathrm{R}_{70}$ values were lessen due to more heat were needed to overcome the additional moisture.

In addition, as shown in Fig. 10, the influence of moisture in gas supplied on $\mathrm{R}_{70}$ and $t_{127}$ values decreased as oxygen concentration increased. This finding has a practical significance in risk assessments of selfheating using adiabatic oxidation approach. The use of gas flow with oxygen well above $21 \%$ can minimize the effect of moisture content in the gas supply.

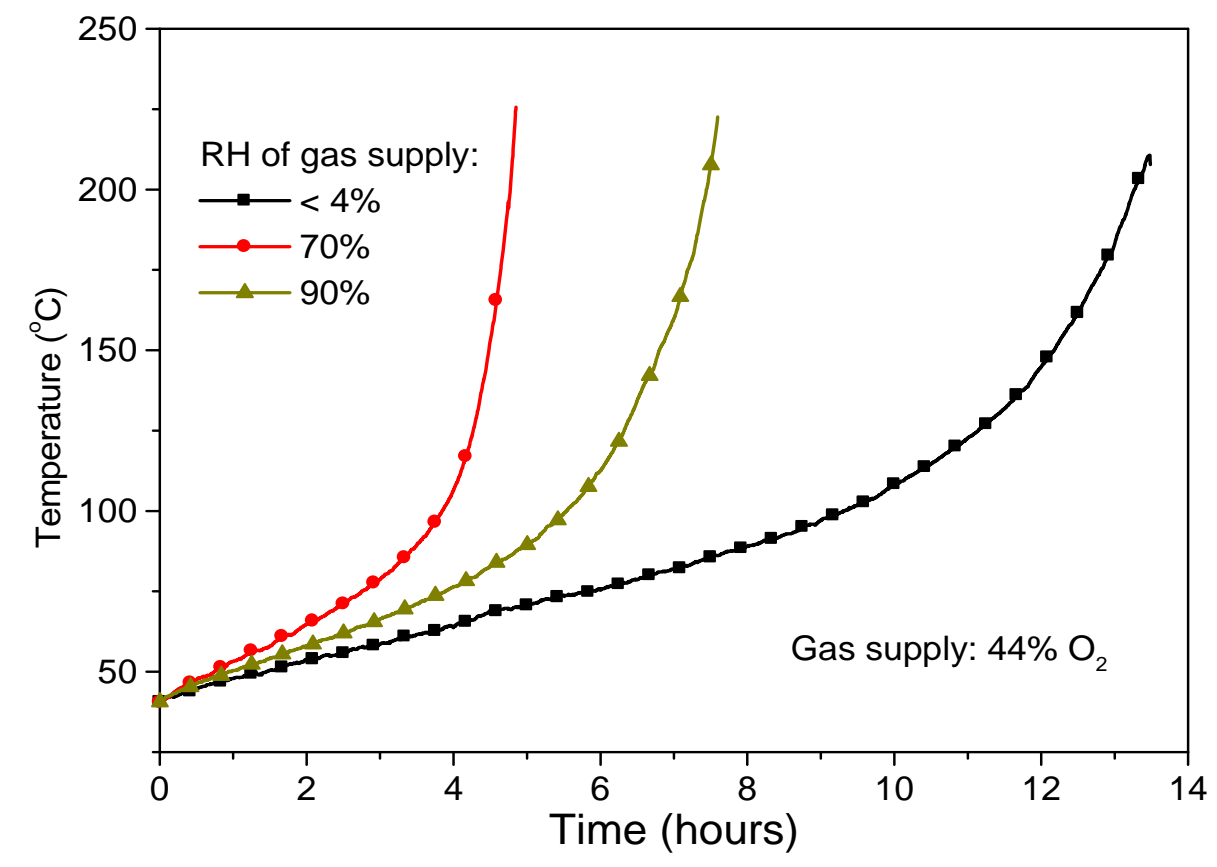

Fig. 8. Self-heating curves showing the effect of relative humidity (RH) in gas supply at a constant oxygen concentration of $44 \%$. 


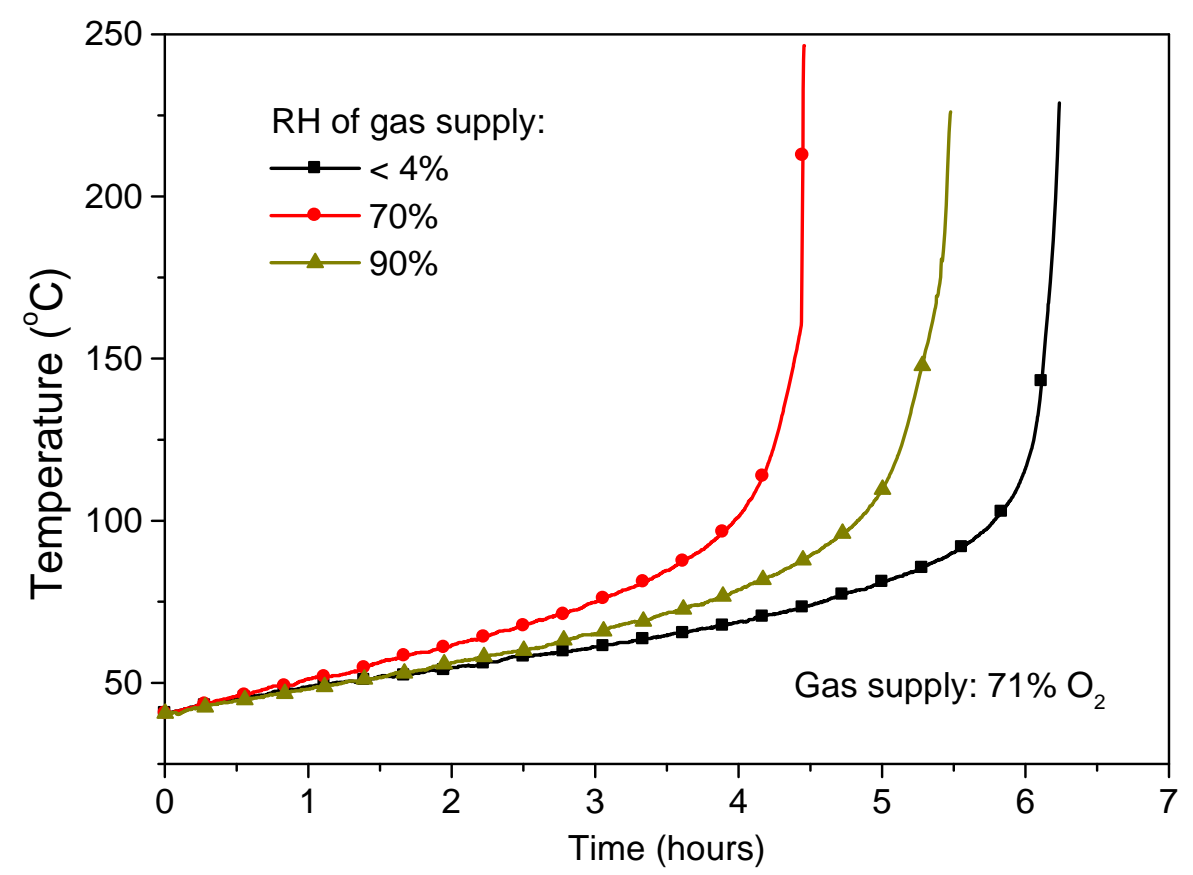

Fig. 9. Self-heating curves showing the effect of relative humidity (RH) in gas supply at a constant oxygen concentration of $71 \%$.

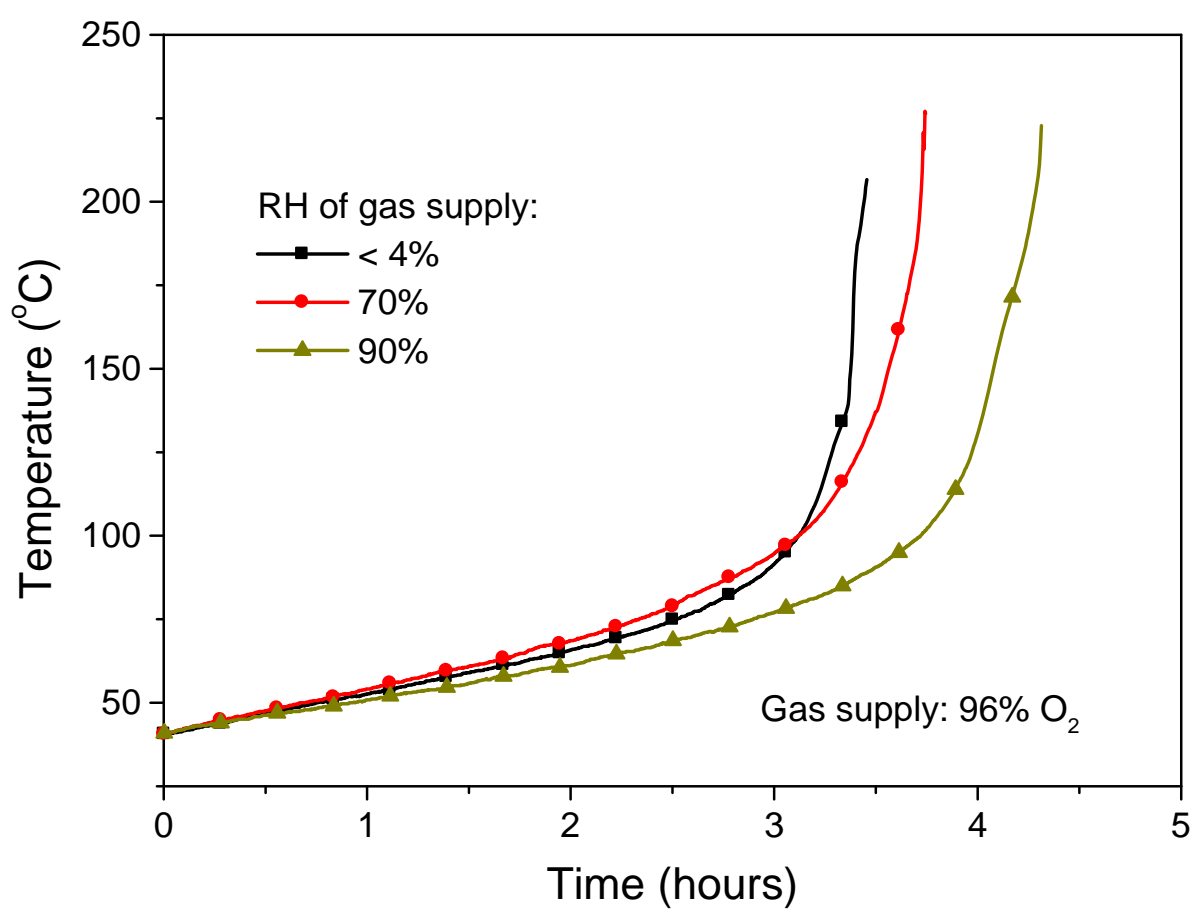

Fig. 10. Self-heating curves showing the effect of relative humidity (RH) in gas supply at a constant oxygen concentration of $96 \%$. 


\section{CONCLUSION}

The adiabatic oxidation method provides important information on the process of self-heating under conditions close to nature. The results of this study show that the sub-bituminous coal tested is extremely reactive to oxygen at various concentrations. This study revealed that humidity of the atmosphere or gas supply plays a key role on the self-heating rates of the coal tested. It is shown that an increase in relative humidity of the oxygen has a marked affect on the self-heating rates of the coal. In this work the subbituminous coal sample undergo oxidation most rapidly when the relative humidity of the gas supply is about $70 \%$. The effect of relative humidity is decreases as oxygen concentration in the gas supply increases. A practical consequence of this finding is that improved fire safety measures should be taken into account especially during stockpiling and long distance transport of sub-bituminous coals in hot and humid regions.

\section{REFERENCES}

[1] Nugroho, Y.S., McIntosh, A.C., and Gibbs, B.M., (2000) Low-temperature Oxidation of Single and Blended Coals, Fuel 79: 1951-1961, http://dx.doi.org/10.1016/S0016-2361(00)00053-3

[2] Clemens, A. H., and Matheson, T.W., (1996), The Role of Moisture in the Self-heating of LowRank Coals, Fuel 75: 891-895, http://dx.doi.org/10.1016/0016-2361(96)00010-5

[3] Küçük, A., Kadığlu, Y., Gülaboğlu, M.Ş., (2003) A Study of Spontaneous Combustion Characteristics of a Turkish Lignite: Particle size, Moisture of Coal, Humidity of Air, Combustion and Flame 133: 255-261, http://dx.doi.org/10.1016/S0010-2180(02)00553-9

[4] Beamish, B.B., Hamilton, G.R., (2005) Effect of Moisture Content on the R ${ }_{70}$ Self-heating Rate of Callide Coal, International Journal of Coal Geology 64: 133- 138, http://dx.doi.org/10.1016/j.coal.2005.03.011

[5] Vance, W. E., Chen, X. D., and Scott, S. C., (1996) The Rate of Temperature Rise of a Subbituminous Coal during Spontaneous Combustion in an Adiabatic Device: The Effect of Moisture Content and Drying Methods, Combustion and Flame Volume 106: 261-270, http://dx.doi.org/10.1016/0010-2180(95)00276-6

[6] Ren, T.X., Edwards, J.S., and Clarke, D. (1999), Adiabatic Oxidation Study on the Propensity of Pulverised Coals to Spontaneous Combustion, Fuel 78: 1611-1620, http://dx.doi.org/10.1016/S0016-2361(99)00107-6

[7] Gray, B.F., Griffiths, J.F. and Hasko, S.M. (1984), Spontaneous Ignition Hazard in Stockpiles of Cellulosic Materials : Criteria for Safe Storage, Journal of Chemical Technology and Biotechnology 34A: 453-463.

[8] Beamish, B.B, Barakat, M.A., St George, J.D., (2000), Spontaneous-combustion Propensity of New Zealand Coals under Adiabatic Conditions, Thermochimica Acta 362: 79-87, http://dx.doi.org/10.1016/S0040-6031(00)00588-8.

[9] Mahidin, Ogaki, Y., Usui, H., Okuma, O., (2003), The Advantages of Vacuum-treatment in the Thermal Upgrading of Low-rank Coals on the Improvement of Dewatering and Devolatilization, Fuel Processing Technology 84: 147-160, http://dx.doi.org/10.1016/S0378-3820(03)00052-3.

[10] Nugroho, Y.S., and Saleh, M., "Effect of Moisture and Initial Temperature on Rate of Spontaneous Combustion of a Low-rank Coal", Proceeding of the $12^{\text {th }}$ National Seminar in Industrial Research and Technology, Yogyakarta, 2006 ISBN 979-95620-3-1, pp. (in Bahasa Indonesia).

[11] Gray, B.F., Sextona, M.J., Halliburton, B., Macaskilla, C., (2002), Wetting-induced Ignition in Cellulosic Materials, Fire Safety Journal 37: 465-479, http://dx.doi.org/10.1016/S03797112(02)00002-4.

[12] McIntosh, A, Gray B.F., Wake, G.C., (1994), Ignition of a combustible material in the presence of a damp atmosphere, Physics Letter A 191:61-70, http://dx.doi.org/10.1016/0375-9601(94)90560$\underline{6}$. 
[13] Nugroho, Y.S., McIntosh, A.C., and Gibbs, B.M., "On the Prediction of Thermal Runaway of Coal Piles of Differing Dimension by Using a Correlation between Heat Release and Activation Energy", Symposium (International) on Combustion, Volume 28, 2000, pp. 2321-2327, http://dx.doi.org/10.1016/S0082-0784(00)80643-8.

[14] Monazam, E.R., (1998), Water Adsorption and Desorption by Coals and Chars, Energy \& Fuels 12:1299-1304, http://dx.doi.org/10.1021/ef9800720. 
